RESEARCH / INVESTIGACIÓN

\title{
Clinical Characteristics and Outcome of SARS-CoV-2 Patients. An Experience from Anbar province - West of Iraq
}

\author{
Hazim Ghazzay ${ }^{1}$, Hamdi Saleh Al Mutori², Mazin Saleh Al- Rudaini², Hamed Al Reesi ${ }^{3}$
}

DOI. 10.21931/RB/2021.06.04.20

\begin{abstract}
The SARS-CoV2 infection emerged in Iraq in February 2020. In this study, we describe the clinical characteristics and outcomes of the initial SARS-CoV2 patients. A total of 529 patients were included in this study from April to August 2020 in Anbar province. Patients were confirmed to be infected in nasal swabs by real-time RT-PCR or chest CT scan findings. The gathered data included the demographic variables (age, sex, residency), presence of comorbidity (hypertension, diabetes mellitus, respiratory illness, coronary heart disease, chronic kidney disease, obesity), and history of contact with a known case of SARS-CoV2. The results showed that $64 \%$ of the patients were males and $36 \%$ were female, $48 \%$ of the patients lied in the age category 40-59 years, 74\% had exposure history, 95\% did not have a history of smoking, 46\% were overweight, $60 \%$ had no comorbidity, $78 \%$ presented with mild/moderate disease, $70 \%$ had typical chest CT scan finding (CO-RAD 5), and 76\% of patients showed positive PCR. The fatality rate is $16 \%$. Most of the patients had a history of exposure to a confirmed case of SARS-CoV2 before the illness. The severity and outcome were correlated with risk factors and comorbidity. Combining chest computed tomography images with the qPCR analysis of nasal swab samples can improve the accuracy of SARS-CoV2 diagnosis.
\end{abstract}

Key words: SARS-CoV-2, Clinical Characteristics, Outcome, West of Iraq.

\section{Introduction}

SARS-CoV2 is a novel virus causing a global pandemic with significant morbidity and mortality. It is a coronavirus from Coronaviridae's family and was first discovered in Wuhan, China, in December 2019; it is also named Covid-19 (Corona Virus Disease 2019) ${ }^{1}$. The discovery of the virus was made after having an increasing number of patients with acute respiratory tract infection not attributed to known viral infections like the influenza virus, avian flu, and severe acute respiratory syndrome coronavirus (SARS-CoV). Lockdown of the area where the disease appeared first with other precautionary measures has failed to contain the virus, and it spread rapidly to other countries in Asia (South Korea, Iran, India, Pakistan, and many others) and then globally,3. In its update in March 2020, the World Health Organization (WHO) declared the disease a pandemic in a press announcement. This is not the first outbreak caused by this kind of viruses in the last 2 decades, since it had been described in 2002 (Severe Acute Respiratory Syndrome Coronavirus (SARS-CoV) and 2012 (the Middle East Respiratory Syndrome Coronavirus (MERS-CoV)). The mortality rate of SARS-CoV was $10 \%$, while that of MERS-CoV was $37 \% 4,5$ The spread of the virus varied enormously among different countries and within the same country or region. However many studies have confirmed that the number of affected cases tremendously overshoots reported cases confirmed by PCR testing ${ }^{6}$.

The average incubation period of the disease is 6 days $^{7}$, but it could be as long as 14 days $^{8}$. Most patients develop only mild symptoms of fever, mild cough, loss of taste and smell sensations, and muscle cramps. Nonetheless, a minority might present with severe pneumonia, acute respiratory distress syndrome, and multi-organ failure ${ }^{9,10}$. Radiologically, bilateral pulmonary parenchymal ground-glass and consolidative pulmonary opacities are the most frequent CT; however, occasionally, rounded morphology and peripheral lung distribution might be evident ${ }^{11,12}$. Iraq reported the first case of covid-19 in late February 2020 in Al-Najaf province. The disease then gradually involved all governorates and provinces. The first confirmed case in Anbar Province (West of Iraq) was on 25th March 2020, and the first death was on 31st May $2020^{13}$. Knowledge of the natural course of the disease and its virulence is essential in organizing proper plans and procedures to face this illness effectively. Studies have shown that Covid-19 has a wide range of disease severity and mortality ${ }^{14}$, representing a fundamental challenge facing health care providers. Several studies were carried out in different parts of Iraq targeting these objectives, and this study represents another one to describe the clinical characteristic and outcomes of the disease in the West of Iraq.

\section{Materials and methods}

Depending on the local protocol, patients who tested positive to SARS-CoV2 using Real-Time Polymerase Chain Reaction (RT-PCR) and patients with classical clinical and radiological features and history of contact with Covid-19 patients (even with negative RT-PCR) were enrolled in this cross-sectional study. We used a CT-based system (CO-RADS ) to assess the suspicion of pulmonary involvement in SARS-CoV2 ${ }^{15}$. Patients were either admitted to Ramadi Teaching Hospital or treated at home based on their clinical status. Those who were treated at home were followed by medical personnel regularly. The management line is based on the Iraqi Ministry of Health's national guidelines for clinical care and treatment of SARSCoV2, updated regularly.

A total of 529 patients were included in this study during the period from April to August 2020. The gathered data included the demographic variables (age, sex, place of living), presence of comorbidity (Hypertension, diabetes mellitus, respiratory illness, coronary heart disease, chronic kidney disea-

\footnotetext{
${ }^{1}$ Department of Medicine, College of Medicine, University Of Anbar, Oman

${ }^{2}$ Department of Medicine, National University for Science and Technology - College of Medicine and Health Sciences, Oman.

${ }^{3}$ Department Studies and Research, Directorate General of Health Services -NBG, Ministry of Health, Oman.
} 
se), and history of contact with a known case of SARS-CoV2. Patients were categorized into 4 categories. Mild disease is when a patient complains of one or more of the following: Low-grade fever, mild cough, rainy nose, and sore throat. The moderate disease is when a patient shows clinical and radiological features of pneumonia without hypoxia: Fever, cough, chest tightness, clinical and radiological evidence of consolidation(s). Severe disease is when a patient shows clinical and radiological features of pneumonia with hypoxia which requires assisted ventilation. Acute disease is when a patient suffers from clinical shock or organ(s) failure ${ }^{16}$. The Human Research and Ethics Committee, Anbar University (Ministry of Higher Education and Scientific Research- Iraq) approved this study (Notification letter No. 69/2020).

\section{Statistical analysis}

It was carried out using SPSS, version 22. Since all variables were of categorical types, the Chi-Square test with a $5 \%$ significance level was used to examine the investigated relationships between patients' characteristics and survival status. If the chi-square test's assumption (expected count) was violated, either Fisher's exact test or likelihood ratio Chi-square test was used as suitable.

\section{Results}

During the study period, 529 patients with SARS COV-2 were either admitted in Ramadi hospital or followed at home. Of them, $64 \%$ were males, $48 \%$ of age $40-59$ years, $74 \%$ with exposure history, 95\% without a history of smoking, 46\% overweight, $60 \%$ without comorbidity, $78 \%$ with mild/moderate covid, 70\% having CO-RAD 5 chest CT scan finding and $76 \%$ with positive PCR. Out of 529 covid-19 patients, $84 \%$ survived, while the remaining $16 \%$ could not survive (case mortality rate is $16 \%$ ).

Table (1) shows the characteristics of SARS-CoV2 patients by survival status. There was no significant difference in the distribution of survival status by gender. The percentage of non-survival increased with age, and the association was significant $(p=0.001)$. The majority of non-survivors had no smoking history. The highest percentage of non-survivors was among overweight patients (35\%), and the difference was statistically significant $(p=0.001)$. Almost all non-survivors (99\%) had at least one comorbidity (hypertension, diabetes, coronary heart disease, chronic obstructive lung disease, chronic kidney disease) compared to $29 \%$ of survivors, and the association was significant $(p=0.001)$.
Table (2) survivors reported less exposure history (72\%) compared to non-survivors (86\%), and the difference was statistically significant $(p=0.008)$. All non-survivors $(100 \%)$ were diagnosed with severe/critical covid-19 status compared to only $8 \%$ of survivors, and the association was significant $(p=0.001)$.

The percentage of non-survivors increased with disease severity, and CORAD level as shown by CT scan as $85 \%$ of non-survivors had CO-RAD 5 ( $p=0.001$ ) (Table 3).

\section{Discussion}

SARS-CoV2 pandemic continues spreading despite all measures exerted by health authorities to face it. Understanding patients' characteristics about the survival rates of the disease is valuable in this confrontation. We are still gaining knowledge in identifying clinical characteristics of severe disease and mortality. This study summarizes the clinical characteristics of 529 cases with SARS-CoV2 infection concerning the outcome, i.e., survivors vs. non-survivors. Knowing these characteristics will have a significant impact on improving survival. The reported overall case fatality in different Iraq provinces is as follows: Southern 9.4\%, Northern 2.1\%, Eastern $16.7 \%$, and the Capital $8.7 \%^{17}$. This study estimated $16 \%$ as a case fatality rate in Anbar province - west of Iraq.

There is a consensus among researchers and clinicians that the increasing age of the patients is significantly linked to a higher non-survival rate in SARS-CoV2 patients ${ }^{18,19}$. Likewise, the current results showed that elderly patients were prone to more severe disease and higher mortality. The possible cause is not well understood; however, viable hypotheses emerge, including changes to the immune cell repertoire, epigenome, nicotinamide adenine dinucleotide (NAD+) levels, and inflammasome activity biological clocks, and covalent modifications of human and viral proteins ${ }^{20}$.

Several studies confirmed that SARS-CoV2 infection is more common in patients with comorbidities1,10,18. This is consistent with the current study. However, the results could not find any dominancy of particular comorbidity over the others in terms of outcome. Factors that could explain this include the increased expression of the angiotensin-converting enzyme-2 (ACE2), cytokine storm, and drug interactions in patients with comorbidities ${ }^{21}$.

Many studies have mentioned that the male gender is one of the risk factors for increased severity and mortality independent of age $\mathrm{e}^{22-24}$. However, this study showed no significant difference in terms of survival status and gender. Similar fin-

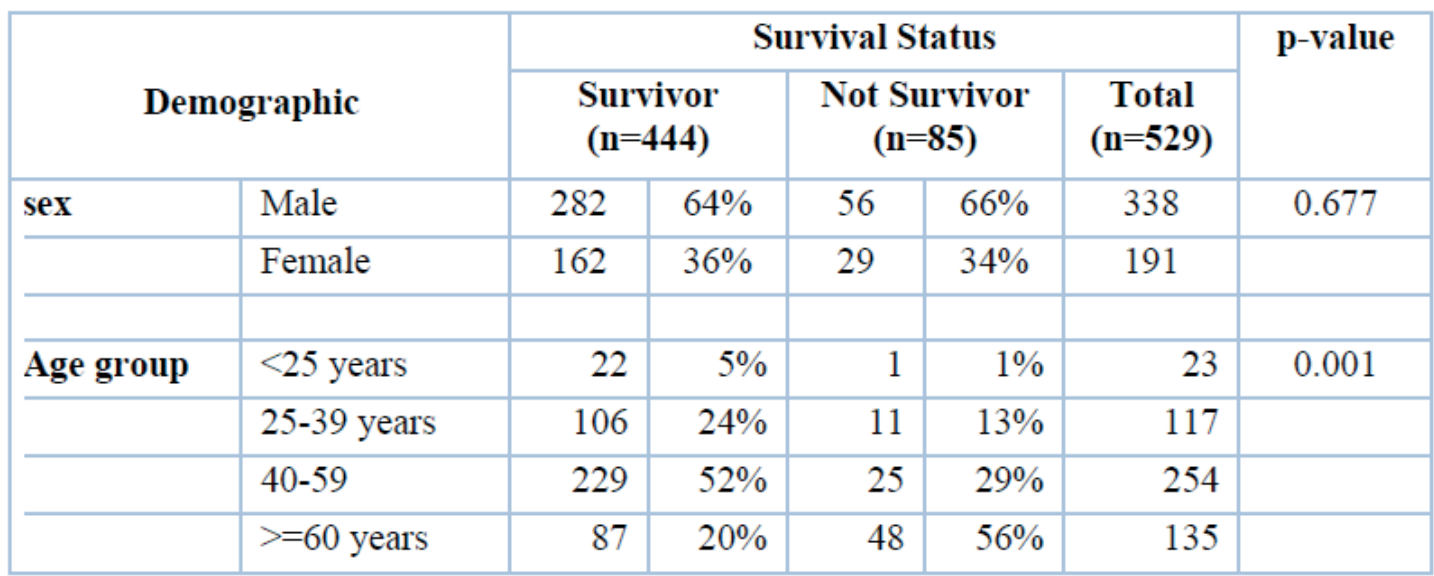

Table 1. Survival status of SARS-CoV2 patients by demographic characteristics. 


\begin{tabular}{|c|c|c|c|c|c|c|c|}
\hline & & \multicolumn{5}{|c|}{ Survival Status } & \multirow{3}{*}{$\begin{array}{c}\text { p-value } \\
0.522\end{array}$} \\
\hline \multicolumn{2}{|c|}{$\begin{array}{c}\text { Risk } \\
\text { Factor's }\end{array}$} & \multicolumn{2}{|c|}{$\begin{array}{l}\text { Survivor } \\
(n=444)\end{array}$} & \multicolumn{2}{|c|}{$\begin{array}{l}\text { Not Survivor } \\
\quad(n=85)\end{array}$} & \multirow{2}{*}{$\begin{array}{c}\begin{array}{c}\text { Total } \\
(\mathbf{n}=\mathbf{5 2 9})\end{array} \\
28\end{array}$} & \\
\hline Smoking & Yes & 24 & $5 \%$ & 4 & $5 \%$ & & \\
\hline & No & 420 & $95 \%$ & 81 & $95 \%$ & 501 & \\
\hline \multirow{4}{*}{$\begin{array}{l}\text { Body } \\
\text { weight/ BMI }\end{array}$} & Normal $(18.5-24.9)$ & 178 & $40 \%$ & 26 & $31 \%$ & 204 & 0.001 \\
\hline & Over weight $(25-29.9)$ & 215 & $48 \%$ & 30 & $35 \%$ & 245 & \\
\hline & Obesity $(30-34.9)$ & 36 & $8 \%$ & 20 & $24 \%$ & 56 & \\
\hline & Morbid Obesity $(+40)$ & 15 & $3 \%$ & 9 & $11 \%$ & 24 & \\
\hline \multirow[t]{2}{*}{ Comorbidity } & Yes & 127 & $29 \%$ & 84 & $99 \%$ & 211 & 0.001 \\
\hline & No & 317 & $71 \%$ & 1 & $1 \%$ & 318 & \\
\hline \multirow[t]{6}{*}{ Comorbidity } & Hypertension & 31 & $7 \%$ & 45 & $53 \%$ & 76 & 0.001 \\
\hline & Diabetes & 21 & $5 \%$ & 55 & $65 \%$ & 76 & 0.001 \\
\hline & Coronary heart disease & 14 & $3 \%$ & 12 & $14 \%$ & 26 & 0.001 \\
\hline & $\begin{array}{l}\text { Chronic obstructive } \\
\text { lung disease }\end{array}$ & 8 & $2 \%$ & 11 & $13 \%$ & 19 & 0.001 \\
\hline & Chronic kidney disease & 4 & $1 \%$ & 2 & $2 \%$ & 6 & 0.248 \\
\hline & $\begin{array}{l}\text { Others(Stroke, Chronic } \\
\text { liver diseases, } \\
\text { Rheumatoid Arthritis } \\
\text { and Malignancies ) }\end{array}$ & 6 & $1 \%$ & 2 & $2 \%$ & 8 & 0.621 \\
\hline
\end{tabular}

Table 2. Survival status of SARS-CoV2 patients by risk factors assessment.

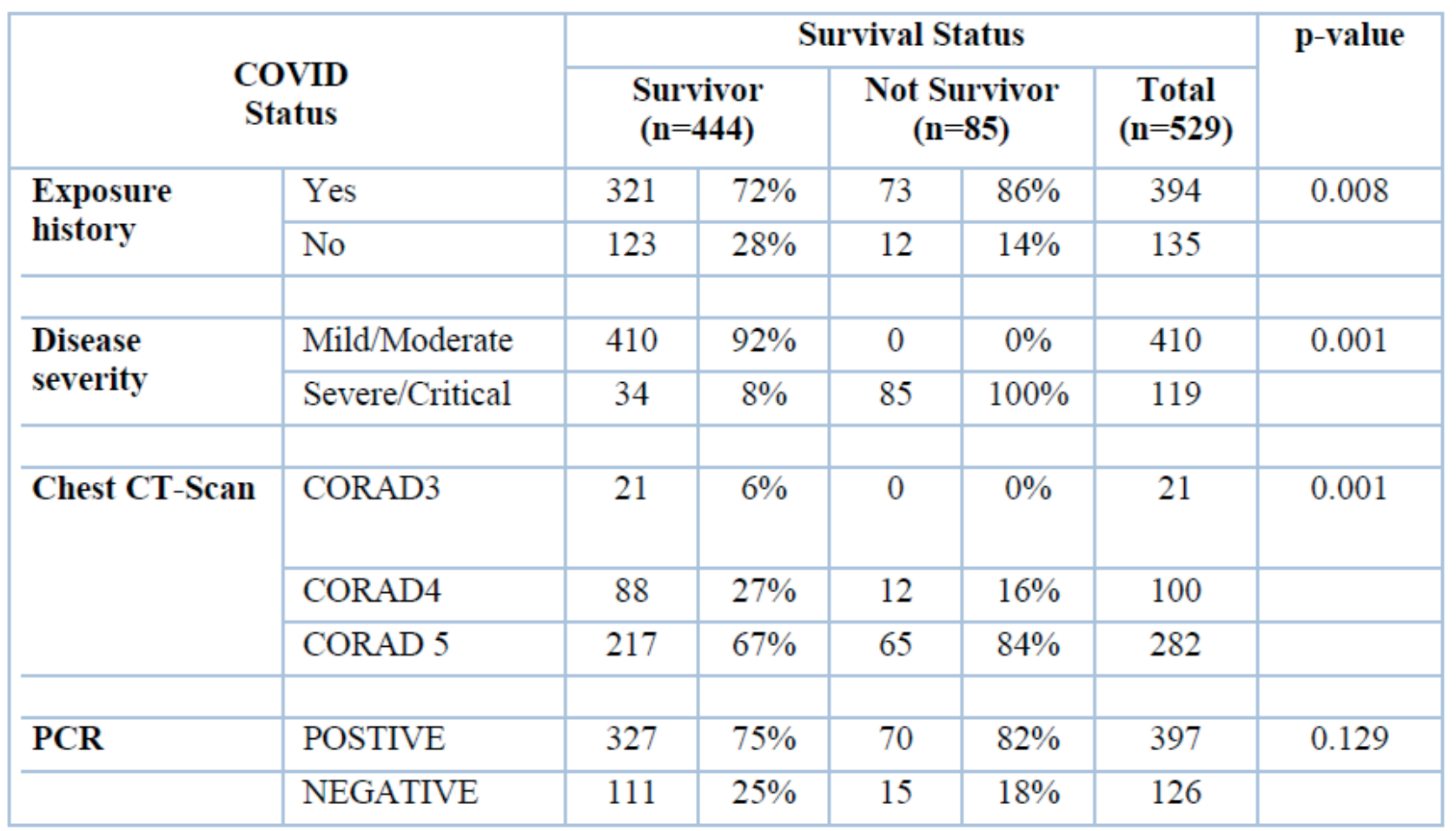

Table 3. Survival status of SARS-CoV2 patients by disease exposure and severity. 
dings have been seen in other studies ${ }^{25-27}$. A possible explanation would be that in certain countries, like Iraq, women are at higher risks due to demographic factors or local health characteristics which has been shown in other studies conducted in other parts of the country ${ }^{17,28}$. The history of smoking was considered as a nasty prognostic factor in numerous studies $^{1,29-32}$. This is in contrast with the current findings, as the majority of non-survivors were a non-smoker. This may be related to the low numbers of smokers in this study compared to non-smokers or incomplete records. In addition to this, severe SARS-CoV2 targets the older population (>65 years), in whom smoking rates are approximately 3-5 fold lower than that in the general population ${ }^{33}$. Obese patients are at higher risk of developing severe and critical illness than non-obese patients ${ }^{34-36}$. A similar finding was shown in this study. This is likely because obese patients are known to have a defective immune system in addition to underlying comorbidities ${ }^{37,38}$. Obesity changes the role of immunity by altering the response of cytokines, resulting in a decrease in the cytotoxic cell response of immuno-competent cells that have a key anti-viral role and disturb the balance of endocrine hormones, like leptin, that affect the interaction between metabolic and immune systems ${ }^{39,40}$. Chest CT scan is a valuable tool in the diagnostic process of viral pneumonia cases associated with SARS-CoV2. The sensitivity and specificity of the chest CT in diagnosing SARS-CoV2 and the radiation exposure have to be judged together. Arguments exist regarding the value of chest CT scan for SARS-CoV2 diagnosis, particularly thosepatients who exhibit typical clinical symptoms and have negative RT-PCR results in highly infected regions ${ }^{41}$.

\section{Conclusions}

The SARS-CoV2 infection caused severe respiratory illness with significant morbidity and mortality. Understanding these factors can enhance defining patients at higher risk and allow a more targeted approach to prevent those deaths. Using chest CT scan images with nasal swab sample qPCR analysis may improve the accuracy of SARS-CoV2 diagnosis.

\section{Conflict of interest}

Authors have no conflict of interest.

\section{Source of funding}

Authors did not receive any funding.

\section{Acknowledgment}

We appreciate all the support and encouragement of the healthcare workers at Anbar Health Institution and Ramadi Teaching Hospital and all patients who participated in our study and their families.

\section{Bibliographic references}

1. Huang C, Wang Y, Li X, Ren L, Zhao J, Hu Y, et al. Clinical features of patients infected with 2019 novel coronavirus in Wuhan, China. Lancet. 2020;395(10223):497-506. doi:10.1016/S01406736(20)30183-5.

2. Cao M, Zhang D, Wang Y, Lu Y, Zhu X, Li Y, et al. Clinical features of patients infected with the 2019 Novel Coronavirus (COVID-19) in Shanghai, China. 2020 [cited 2020 6th July]. Doi: 10.1101/2020.03.04.20030395.
3. Johns Hopkins Coronavirus Resource Center. COVID-19 Map.Retrieved From: https://coronavirus.jhu.edu/map.html. Accessed: 15th December 2020.

4. Zhu N, Zhang D, Wang W, Li X, Yang B, Song J, et al. A novel Coronavirus from patients with pneumonia in China, 2019. N Engl $J$ Med. 2020;382(8):727-33. Doi: 10.1056/NEJMoa2001017.

5. Drosten C, Meyer B, Müller MA, Corman VM, Al-Masri M, Hossain R, et al. Transmission of MERS-coronavirus in household contacts. N Engl J Med. 2014;371(9):828-35. Doi: 10.1056/NEJMoa1405858

6. John PA. Global perspective of COVID囚19 epidemiology for a full囚cycle pandemic. Eur J Clin Invest. 2020;50(12):e13423. Doi: 10.1111/eci.13423.

7. Wassie GT, Azene AG, Bantie GM, Dessie G, Aragaw AM. Incubation Period of Severe Acute Respiratory Syndrome Novel Coronavirus 2 that Causes Coronavirus Disease 2019: A Systematic Review and Meta-Analysis. Curr Ther Res Clin Exp. 2020; 93:100607. Doi: 10.1016/j.curtheres.2020.100607.

8. Chan JF, Yuan S, Kok KH, To KK, Chu H, Yang J, et al. A familial cluster of pneumonia associated with the 2019 novel coronavirus indicating person-to-person transmission: a study of a family cluster. Lancet. 2020;395(10223):514-23. Doi: 10.1016/S01406736(20)30154-9

9. Rodriguez-Morales AJ, Cardona-Ospina JA, Gutierrez-Ocampo E, Villamizar-Pena R, Holguin-Rivera Y, Escalera-Antezana JP, et al. Clinical, laboratory and imaging features of COVID-19: a systematic review and meta-analysis. Travel Med Infect Dis. 2020; 34:101623. Doi: 10.1016/j.tmaid.2020.101623.

10. Chen N, Zhou M, Dong X, Qu J, Gong F, Han Y, et al. Epidemiological and clinical characteristics of 99 cases of 2019 Novel coronavirus pneumonia in Wuhan, China: a descriptive study. Lancet. 2020; 395(10223):507-13. Doi: 10.1016/S0140-6736(20)302117.

11. Chung M, Bernheim A, Mei X, Zhang N, Huang M, Zeng X, et al. CT imaging features of 2019 novel coronavirus (2019-nCoV). Radiology. 2020; 295(1):202-7. Doi: 10.1148/radiol.2020200230

12. Lei J, Li J, Li X, Qi X. CT imaging of the 2019 novel coronavirus (2019-nCoV) pneumonia. Radiology. 2020;295(1):18. Doi:10.1148/ radiol.2020200236

13. Al Hijaj BAA, Al-Rubaye AK, Al-Hashim ZT, Mohammed MA, Habib OS. A Study on 696 COVID-19 Cases in Basrah-Southern Iraq: Severity and Outcome Indicators. Iraqi Natl J Med. 2020;2(3):16-26. Doi: 10.37319/iqnjm.2.CSI.3

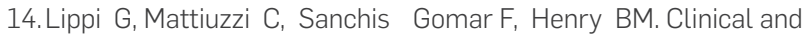
demographic characteristics of patients dying from COVID-19 in Italy vs China: letter to the editor. J Med Virol. 2020; 92:17591760. Doi: 10.1002/jmv.25860.

15. Prokop $M$, van Everdingen W, van Rees Vellinga T, Quarles van Ufford H, Stöger L, Beenen L, et al. . CO-RADS: a categorical CT assessment scheme for patients suspected of having COVID-19-definition and evaluation. Radiology. 2020;296(2):E97104. Doi:10.1148/radiol.2020201473

16. Zu ZY, Jiang MD, Xu PP, Chen W, Ni QQ, Lu GM, et al. Coronavirus Disease 2019 (COVID-19): A Perspective from China, Radiology. 2020 Aug;296(2):E15-E25. Doi: 10.1148/radiol.2020200490

17. Habib OS, AlKanan AK, Abed AH, Mohammed NQ. Epidemiological features of COVID-19 epidemic in Basrah province-southern Iraq-first report. Med. J. Basrah Univ. 2020; 38 (1): 6-17. Doi: 10.33762/mjbu.2020.126943.1008.

18. Qin C, Zhou L, Hu Z, Zhang S, Yang S, Tao Y, et al. Dysregulation of Immune Response in Patients with Coronavirus 2019 (COVID-19) in Wuhan, China. Clin Infect Dis. 2020 Jul 28;71(15):762-768. Doi: 10.1093/cid/ciaa248.

19. Zhang G, Zhang J, Wang B, Zhu X, Wang Q, Qiu S. Analysis of clinical characteristics and laboratory findings of 95 cases of 2019 novel coronavirus pneumonia in Wuhan, China: a retrospective analysis. Respir Res. 2020;21(1):1-10.

20. Mueller AL, McNamara MS, Sinclair DA. Why does COVID-19 disproportionately affect older people?. Aging (Albany NY). 2020;12(10):9959-9981. Doi:10.18632/aging.103344. 
21. Alyammahi SK, Abdin SM, Alhamad DW, Elgendy SM, Altell AT, Omar HA. The dynamic association between COVID-19 and chronic disorders: An updated insight into prevalence, mechanisms and therapeutic modalities. Infect Genet Evol. 2021; 87:104647. Doi: 10.1016/j.meegid.2020.104647.

22. Poblador-Plou B, Carmona-Pirez J, loakeim-Skoufa I, Poncel-Falco A, Bliek-Bueno K, Cano-Del Pozo M, et al. Baseline chronic comorbidity and mortality in laboratory-confirmed COVID-19 cases: Results from the PRECOVID study in Spain. Int J Environ Res Public Health. 2020;17(14): 5171. Doi: 10.3390/ijerph17145171

23. Jin JM, Bai P, He W, Wu F, Liu XF, Han DM, et al. Gender differences in patients with COVID-19: Focus on severity and mortality. Front Public Health. 2020; 8: 152. Doi: 10.3389/fpubh.2020.00152.

24. Leung, C. Risk factors for predicting mortality in elderly patients with COVID-19: A review of clinical data in China. Mech. Ageing Dev. 2020 Jun; 188:111255. Doi: 10.1016/j.mad.2020.111255.

25. Du RH, Liang LR, Yang CQ, Wang W, Cao TZ, Li M, et al. Predictors of mortality for patients with COVID-19 pneumonia caused by SARS-CoV-2: a prospective cohort study. Eur Respir J. 2020 7th May;55(5):2000524. Doi: 10.1183/13993003.00524-2020.

26. Martins-Filho PR, Tavares CSS, Santos VS. Factors associated with mortality in patients with COVID-19. A quantitative evidence synthesis of clinical and laboratory data. Eur J Intern Med. 2020; 76:97-9. Doi.: 10.1016/j.ejim.2020.04.043.

27. Huang JF, Wang XB, Zheng KI, Liu WY, Chen JJ, George J, et al. Letter to the Editor: Obesity hypoventilation syndrome and severe COVID-19. Metabolism. 2020 Jul; 108:154249. Doi: 10.1016/..metabol.2020.154249.

28. Dehingia N, Raj A. Sex differences in COVID-19 case fatality: do we know enough? Lancet Glob Health. 2021 Jan; 9(1):e14-e15. Doi: 10.1016/S2214-109X (20)30464-2.

29.Zhou F, Yu T, Du R, Fan G, Liu Y, Liu Z, et al. Clinical course and risk factors for mortality of adult inpatients with COVID-19 in Wuhan, China: a retrospective cohort study. Lancet. 2020 Mar 28; 395(10229):1054-1062. Doi: 10.1016/S0140-6736(20)30566-3.

30.Zhang JJ, Dong X, Cao YY, Yuan YD, Yang YB, Yan YQ, et al. Clinical characteristics of 140 patients infected with SARS-CoV-2 in Wuhan, China. Allergy. 2020 Jul;75(7):1730-1741. Doi: 10.1111/ all.14238.

31. Guan WJ, Ni ZY, Hu Y, Liang WH, Ou CQ, He JX, et al. China Medical Treatment Expert Group for Covid-19. Clinical Characteristics of Coronavirus Disease 2019 in China. N Engl J Med. 2020 Apr 30; 382(18):1708-1720. Doi: 10.1056/NEJMoa2002032.
32. Liu W, Tao ZW, Wang L, Yuan ML, Liu K, Zhou L, et al. Analysis of factors associated with disease outcomes in hospitalized patients with 2019 novel coronavirus disease. Chin Med J (Engl). 2020 May 5; 133(9):1032-1038. Doi: 10.1097/CM9.0000000000000775.

33. Leung JM, Yang CX, Sin DD. Reply to: "Current smoking is not associated with COVID-19". Eur Respir J. 2020; 55: 2001340. Doi: 10.1183/13993003.01340-2020.

34. Schiffl, H., Lang, S.M. Obesity, acute kidney injury and outcome of critical illness. Int Urol Nephrol. 2017; 49:461-466. Doi: 10.1007/ s11255-016-1451-4

35. Gharib M, Kaul S, LoCurto J, Perez M, Hajri T. The obesity factor in critical illness: between consensus and controversy. J Trauma Acute Care Surg. 2015; 78:866-73. Doi: 10.1097/ TA.0000000000000597.

36. Feng Gao, Kenneth I. Zheng, Xiao-Bo Wang, Qing-Feng Sun, KeHua Pan, Ting-Yao Wang, et al. obesity Is a Risk Factor for Greater COVID-19 Severity. Diabetes Care. Jul 2020; 43 (7) e72-e74. Doi: 10.2337/dc20-0682.

37. Fortis A, Garcia-Macedo R, Maldonado-Bernal C, Alarcon-Aguilar F, Cruz M. The role of innate immunity in obesity. Salud Publica Mex. 2012; 54(2):171-7. Doi: 10.1590/s003636342012000200014

38. Sattar N, Mclnnes IB, McMurray JJV. Obesity a risk factor for severe COVID-19 infection: multiple potential mechanisms. Circulation. 2020; 142:4-6. Doi: 10.1161/CIRCULATIONAHA.120.047659.

39.Rojas-Osornio SA, Cruz-Hernandez TR, Drago-Serrano ME, Campos-Rodriguez R. Immunity to influenza: impact of obesity. Obes Res Clin Pract. 2019; 13(5):419-29. Doi: 10.1016/j. orcp.2019.05.003

40.Karagiannides I, Pothoulakis C. Obesity, innate immunity and gut inflammation. Curr Opin Gastroenterol. 2007 Nov;23(6):661-6. Doi: 10.1097/MOG.0b013e3282c8c8d3.

41. Kovács A, Palásti P, Veréb D, Bozsik B, Palkó A, et al. The sensitivity and specificity of chest CT in the diagnosis of COVID-19. Eur Radiol. 2020:31(5): 2819-2824. Doi.org/10.1007/s00330-02007347-x

Received: 9th July 2021

Accepted: 10 August 2021 